American Journal of Applied Sciences 8 (4): 382-392, 2011

ISSN 1546-9239

(C) 2010 Science Publications

\title{
Implementation Weather-Type Models of Capacitated Arc Routing Problem via Heuristics
}

\author{
${ }^{1}$ Zuhaimy Ismail and ${ }^{2}$ Mohammad Fadzli Ramli \\ ${ }^{1}$ Department of Mathematics, Faculty of Science, University Technology Malaysia, \\ 81310 Johor Bahru, Johor, Malaysia \\ ${ }^{2}$ Institute of Engineering Mathematics, University Malaysia Perlis, \\ 02000 Kuala Perlis, Perlis, Malaysia
}

\begin{abstract}
Problem statement: In this study, we introduced a new and real-life condition of Capacitated Arc Routing Problem (CARP), a model that represents vehicle's operation in waste collection. In general, we studied the element of rain drops that affected the collected waste weight in total by imposed a new variable namely rainy weight age. In rainy days, the household refusals did not increase in volumes, but in weights due to rain drops. Consequently, this matter thus burdened vehicle's capacity and prolonged its operation time. This dynamic variable thus changes the initial CARP model where the existing model did not consider other external elements that have effected onto the model. Approach: Then we developed and enhanced CARP by integrating stochastic demand and time windows to suit the models with our specific case. Results: Objectively, CARP with stochastic demand (CARPSD) and CARP with time windows (CARPTW) were designed to minimize the total routing cost and number of trips for a vehicle. Our approach is to design CARP models in almost likely to road layout in residential area and graphically this model is called mesh network. We also developed a constructive heuristic that is called nearest procedure based on highest demand/cost (NPHDC) and work in conjunction with switching rules to search the feasible solution. Conclusion: Our preliminary results show a higher cost and more trips are needed when the vehicle operates in rainy day compared to normal day operation.
\end{abstract}

Key words: Arc routing problem, waste collection, stochastic demand, time windows, Vehicle Routing Problem (VRP), CARP model, rainy weight age, penalty cost

\section{INTRODUCTION}

Managing waste is a mammoth task as it needs to be collected, transported and finally disposed of. Beltrami and Bodin (1974) were firstly introduced Vehicle Routing Problem (VRP) in municipal waste collection in New York City where 25,000 tons of waste needed to be collected. In general, Capacitated Arc Routing Problem (CARP) is another kind of routing problem specifically designed to formulate vehicle routing operation in solid waste collection or snow plow. This routing model was introduced by Golden and Wong (1981) and considered as a special domain of VRP but on the other hand, CARP has been comparatively neglected. Since then, CARP progressed in theory and applications and had shown important roles in waste collection industry. Some of the latest developments and applications of CARP could be seen in Letchford and Oukil (2009); Christiansen et al. (2009); Santos et al. (2010); and Gouveia et al. (2010).
However, very few researches considered external factors (such like weather and temperature) in modeling CARP. To our knowledge, Amponsah and Salhi (2004) has considered element of hot weather in modeling CARP and developed a constructive heuristic based on look ahead strategy which takes into account the environmental aspect as well as the cost to solve the routing of garbage collection. Another work is done by Hsu et al. (2007) where the time-varying temperatures and human interaction during cargo opening have affected onto VRP model. However, their work was done onto food transportation and in contrary was applied to VRP which in practice its vehicle's operation is difference to CARP. By this means, this study tries to investigate the influence of rainy weather onto vehicle's operation in waste collection. Objectively, this study aims to determine the total cost for a vehicle and constructing the routes that minimizes the total trips needed to complete the services for both weather-type operations.

Corresponding Author: Zuhaimy Ismail, Department of Mathematics, Faculty of Science, Universiti Teknologi Malaysia, 81310 Johor Bahru, Johor, Malaysia Tel: $+607-5534524$ 
Am. J. Applied Sci., 8 (4): 382-392, 2011

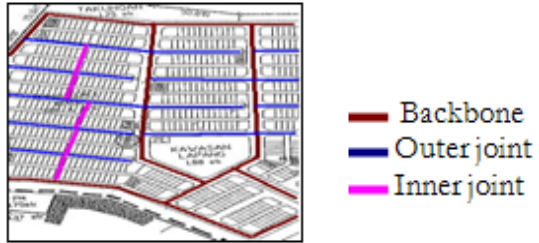

Fig. 1: Common layout of residential houses in Malaysia

CARP and VRP are coexist with the same purpose but originated from different problem background. In CARP, customers' demands are located along the arcs and the vehicle is giving its service when it moves from one arc to another. While VRP, which is also known as node based routing; the vehicle is giving its service when it arrives at a certain node or point. In other words, in waste collection from CARP point of view, the customers are located along the arcs, not at the nodes. Both are NP-hard problems, rich in research and no method could be claimed as the best so far. A method usually fit for one specific problem and only suit for a certain routing model. Met heuristic methods such as tabu search or genetic algorithms however are the popular solutions used by mathematician in order to find the optimal routing path of the vehicles and to seek the lowest cost.

The mathematical structure of CARP is a network graph where each junction is jointed by a point (node) and lines are drawn connecting two nodes, called arcs or edges. The operation of the vehicle starts and ends at the depot, $\mathrm{O}$ and services each arc only once. The customers' demands (or quantity of garbage), $\mathrm{q}_{\mathrm{ij}}>0$ and service cost, $c_{i j}>0$ are associated to every arcs. The total demand, Q must not exceed the capacity of the vehicle, $\mathrm{W}$, that is $\mathrm{Q} \leq \mathrm{W}$. In CARP, each arc in the graph can be traveled in both direction and each vertex corresponds to a road junction (node). Some variants extensions on CARP also can be seen Lacomme et al. (2005); Chu et al. (2006) where periodic CARP (PCARP) was applied; Bautista et al. (2008) and Christiansen et al. (2009) solved mixed CARP (MCARP) and CARPSD respectively.

This study also describes a new model of CARP, by introducing a mesh network which approximately represents the layout of resident houses area in Malaysia. Basically, the houses are located side by side along the road and each road is connected by a main road as the backbone (Fig. 1).

\section{MATERIALS AND METHODS}

Data source: The primary data is a real-life observation on solid waste collection in Johor Bahru, the capital city of Johor, Malaysia for 32 operational days. We collected the raw data onto one identical truck operation in waste collection sub-contractor in South Johor. We delivered our study on one residential area in Johor Bahru that 1266 houses involved in this research. The Table 1 below displays primary or raw data for one identical truck in 32 operational days.

Table 1 clearly shows that $40 \%$ of operations in rainy days increased the service time between 108 to 112 minutes, which is only 100-103 minutes in normal days. The truck travelled longer distance in rainy days in order to complete its services as compared to normal days. This can be seen where approximately $56 \%$ of operation days is more than 5 kilometres routing distance during rainy days. In contrary during normal days, usually it was below $5 \mathrm{~km}$ distance covered. Moreover, the truck carried over capacity is $86 \%$ in rainy days compared to only $24 \%$ in good and clear weather. Table 2 below depicts the mean, minimum and maximum value for serviced time $\left(\mathrm{t}_{\mathrm{s}}\right)$, routing distance (D) and customers' demand or quantity on arc (q) for both normal and rainy operation days. The mean for $t_{s}, D$ and $q$ during rainy days is higher when compared to normal days. In summary, the vehicle serviced longer time during rainy days; traveled in longer distance and had higher customers' demands if compared to normal days.

Next, we pursue to distribution analysis in order to recognise the different behaviour of both kinds operations. This analysis examined the $\mathrm{t}_{\mathrm{s}}, \mathrm{D}$ and $\mathrm{q}$ by distinguished the weather-type data according to a certain distribution. We carried out this analysis because of two purposes. Firstly, the analysis tries to identify which distributions to use for generating the test instances in order to be able to give a consistent and precise description of the developed system. Secondly, it is paramount importance to provide CARP models with the necessary and accurate information before constructing the models. We reported the findings.

Problem identification: The conducted interview from the case study and primary data had shown the significant routing problem when it comes to a rainy day. In rainy day, rain drops into the open garbage or open bin and increased the waste weights. Similar condition happens when the open-top container truck is used to picking-up the waste. In other words, the household refusal in rainy day did not increase in volumes, but in weights due to rain drops. This variable thus affected the vehicle's capacity in total. 
Am. J. Applied Sci., 8 (4): 382-392, 2011

Table 1: Primary data for an identical truck in 32 operational days

\begin{tabular}{|c|c|c|c|c|c|c|c|c|c|}
\hline$\overline{\text { Day }}$ & weather & $t_{s}$ & $\mathrm{D}$ & $\mathrm{q}$ & Day & weather & $\mathrm{t}_{\mathrm{s}}$ & $\mathrm{D}$ & $q$ \\
\hline 1 & $\mathrm{hr}$ & 104 & 4980 & $* 5390$ & 17 & $\mathrm{hr}$ & 109 & 4800 & $* 6280$ \\
\hline 2 & $g$ and $c$ & 106 & 4970 & 4520 & 18 & $\mathrm{~g}$ and $\mathrm{c}$ & 99 & 4120 & 4875 \\
\hline 3 & gandc & 101 & 5070 & 3900 & 19 & $\mathrm{~g}$ and $\mathrm{c}$ & 102 & 3980 & 4725 \\
\hline 4 & gandc & 102 & 4770 & $* 6080$ & 20 & $\mathrm{r}$ & 110 & 5030 & $* 5235$ \\
\hline 5 & $\mathrm{r}$ & 111 & 5130 & 4520 & 21 & $\mathrm{~g}$ and $\mathrm{c}$ & 98 & 4350 & 3890 \\
\hline 6 & $\mathrm{hr}$ & 105 & 4610 & $* 5560$ & 22 & $\mathrm{hr}$ & 117 & 5060 & $* 6800$ \\
\hline 7 & $\mathrm{hr}$ & 114 & 5420 & *7105 & 23 & $\mathrm{hr}$ & 108 & 4910 & $* 6105$ \\
\hline 8 & gandc & 112 & 4920 & 5010 & 24 & $\mathrm{~g}$ and $\mathrm{c}$ & 101 & 4210 & 4200 \\
\hline 9 & gandc & 100 & 4440 & 4360 & 25 & $\mathrm{~g}$ and $\mathrm{c}$ & 104 & 4320 & $* 5400$ \\
\hline 10 & $\mathrm{hr}$ & 109 & 5040 & *5875 & 26 & $\mathrm{r}$ & 113 & 5080 & $* 5490$ \\
\hline 11 & gandc & 104 & 4730 & 4110 & 27 & $\mathrm{~g}$ and $\mathrm{c}$ & 99 & 4450 & 4390 \\
\hline 12 & gandc & 100 & 4540 & 4980 & 28 & $\mathrm{~g}$ and $\mathrm{c}$ & 102 & 4790 & $* 5400$ \\
\hline 13 & $\mathrm{hr}$ & 108 & 4980 & *6960 & 29 & $\mathrm{r}$ & 104 & 5060 & $* 5235$ \\
\hline 14 & gandc & 99 & 4480 & 4005 & 30 & $\mathrm{~g}$ and $\mathrm{c}$ & 97 & 4380 & 4020 \\
\hline 15 & gandc & 103 & 4950 & 4000 & 31 & $\mathrm{hr}$ & 120 & 5180 & $* 6800$ \\
\hline 16 & $\mathrm{hr}$ & 116 & 5600 & $* 7400$ & 32 & $r$ & 108 & 5110 & $* 5250$ \\
\hline
\end{tabular}

Table 2: $\mathrm{t}_{\mathrm{s}}, \mathrm{D}$ and $\mathrm{q}$ for normal and rainy operation days

\begin{tabular}{|c|c|c|c|}
\hline \multirow{2}{*}{$\begin{array}{l}\text { Weather } \\
\text { Variable }\end{array}$} & \multicolumn{3}{|l|}{ Normal } \\
\hline & Mean & Min. & Max. \\
\hline$t_{s}$ & 102.00 & 97 & 112 \\
\hline D & 4560.59 & 3980 & 5070 \\
\hline Q & 4602.65 & 3890 & 6080 \\
\hline$t_{s}$ & 110.93 & 104 & 120 \\
\hline D & 5062.00 & 4610 & 5600 \\
\hline Q & 5975.00 & 4520 & 7400 \\
\hline
\end{tabular}

Chaotic routing frequently occurs in rainy days due to uncertainty in customers' demands. During the good and clear weather, the total quantity $\Sigma \mathrm{q}_{\mathrm{ij}} \leq \mathrm{W}$, where W is the truck maximum capacity. The demand or quantity $\mathrm{q}_{\mathrm{ij}}$ is probabilistic to a certain distribution and $\mathrm{W}$ is a fixed constant. However, rain drops or water level is the new variable that affected the total weight of collected garbage and changed normal day stochastic.

This problem inherits the time window issue as the longer service time (because of more trips) consequently prolonged the total operational time. In time windows problem, the arcs requiring service have to be serviced between certain time duration. In our case, the truck must operate in a specific time window constraints due to a limited time of disposal activity. Due to security reason, the dumpsite will be closed at 5 $\mathrm{pm}$, so all activities must be completed before that hour. Thus, $1 \leq t_{p} \leq 9$, where $t_{p}$ is the total operational time allowed that is from $8-5 \mathrm{pm}$. The significance problems arise when the truck driver has to re-route from initial plan in order to collect the highest demand of waste before proceeds to disposal activity. Sometimes during rainy day, the truck did not complete their zone collection in one trip due to overload carriage and limited of time. In addition, sometimes the truck also failed to transport the loads to the dumpsite in the same operation day. By this means, this incomplete task needs to be continued on the next operation day (next morning) and the truck must start its collection from the uncovered yesterday routes (if occurs).

This different scenario of weather-type needs to be further examined in order to recognize and segregate the model of arc routing problem. Similar case study could be seen in Irhamah and Ismail (2009) and Ismail and Irhamah (2008). This research tries to refine CARP model with stochastic demand (CARPSD) and CARP with time windows (CARPTW) according to specific case of truck operation in waste collection by taking into account the element of rain drops.

Research approach: Firstly, in rainy day, customers' demands become more dynamic and change the normal day behavior. The rain drops increased the customers' demands and hence burdened vehicle's capacity in total. In this study, we define a rainy day as a day with rainfall amount equals to or exceeds $0.1 \mathrm{~mm}$ as a standard determined by Department of Statistics Malaysia, 2007.

Rainy weightage: We simply implemented this character onto vehicle operation by measuring the water level in the truck's leach tank. For modeling purpose, we imposed rain drops weightage, $r$ and the scale is given as $0.1 \leq r \leq 1.0$. The $r$ variable suggests that the quantity of collected garbage $\mathrm{q}_{\mathrm{ij}}$ might increase in maximum double drastically and exceeds the truck capacity during rainy day operation. Stochastic demands become more dynamic and vary to a certain distribution and change the normal day pattern. 
Am. J. Applied Sci., 8 (4): 382-392, 2011

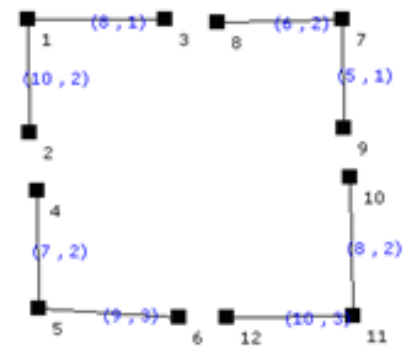

(a)

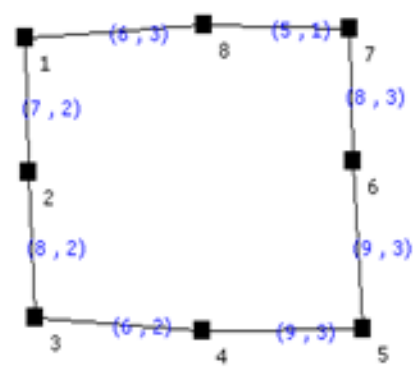

(b)

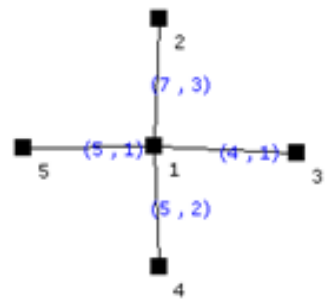

(c)

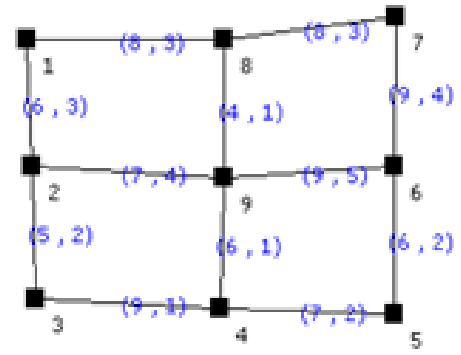

(d)

To differentiate the calculation of collected demands between normal and rainy days, we provide this example. In normal weather, the capacitated quantity of the customers' demands is given by $\Sigma \mathrm{q}_{\mathrm{ij}} \leq \mathrm{W}$. Let say the initial collected demand in normal weather is $\mathrm{q}_{\mathrm{ij}}=1500 \mathrm{~kg}$ and the vehicle's capacity, $\mathrm{W}$ is fixed to $3000 \mathrm{~kg}$. Let say during a rainy day which rainfall amount equals to $0.5 \mathrm{~mm}$, the inequation of collected demands is given by inequation $\mathrm{r} . \mathrm{q}_{\mathrm{ij}}+\Sigma \mathrm{q}_{\mathrm{ijj}} \leq \mathrm{W}$, where $\mathrm{r}[\min , \max ]=\mathrm{r}[0.1,1.0]$. Thus, for $\mathrm{r}=0.5,0.5(1500)+$ $1500=2250 \mathrm{~kg}$. So, the total estimate quantity which affected by rain drops equal to $0.5 \mathrm{~mm}$ is $2250 \mathrm{~kg}$. This amount is not exceeding the total capacity, $\mathrm{W}=3000 \mathrm{~kg}$, but however increased 750 more kilograms of weight. This inequation explained why the collected demands (or household refusals) are heavier during rainy day when compared to good weather day operation.

Secondly, in rainy days, the operational time of the vehicle is longer than normal days because more trips are needed to accomplish all collections. This situation then prolonged the normal time window. This time window constraints increase the complexity of determining optimal delivery routing. In this research, CARP with time window (CARPTW) is formulated and the penalty cost, $\mathrm{P}$ is implemented if the lateness occurs.

Problem statement: From the above explanation, we choose CARPSD and CARPTW to represent our waste collection operational problem. The proposed and redefine models are designed to seek the solutions for rainy days of this question; How to optimize the route plan and minimize the total cost and trips in rainy days? Then, we developed an Exact Algorithm (EA) namely nearest procedure based on highest demand/cost ratio (NPHDC) which work in conjunction with switching rules to search for feasible solution. Algorithms for dynamic CARP are considerably more intricate than deterministic and it calls for efficient algorithm that is able to work in accepted reasonable time since the immediate requests could be provided.

Modeling CARP according to mesh network: The structure of a mesh network is assembled by three components; corner, outer and inner (Fig. 2a-d). A complete but simple mesh network of 9 nodes and 12 arcs as depicts in Fig. 2d. Hence, we redefine our CARP according to Hertz et al. (2000) as an undirected graph, $\mathrm{G}=(\mathrm{V}, \mathrm{E})$ where $\mathrm{V}=\left\{\mathrm{v}_{\mathrm{o}}, \mathrm{v}_{1}, \mathrm{v}_{2}, \ldots, \mathrm{v}_{\mathrm{n}}\right\}$ is a vertex set and $A=\left\{v_{i j} \in V, i \neq j\right\}$ is an arc set. Vertex $v_{1}$, $\mathrm{v}_{3}, \mathrm{v}_{5}$ and $\mathrm{v}_{7}$ are the vertices corner, $\mathrm{V}_{\mathrm{C}}$ where $\mathrm{V}_{\mathrm{C}} \in \mathrm{V}$. Vertex $\mathrm{v}_{2}, \mathrm{v}_{4}, \mathrm{v}_{6}$ and $\mathrm{v}_{8}$ are the outer, $\mathrm{V}_{\mathrm{T}}$ where $\mathrm{V}_{\mathrm{T}} \in \mathrm{V}$. Lastly, $\mathrm{v}_{9}$ is the inner vertex, $\mathrm{V}_{\mathrm{N}}$ where $\mathrm{V}_{\mathrm{N}} \in \mathrm{V}$, thus $\left(\mathrm{V}_{\mathrm{C}}\right.$ , $\left.\mathrm{V}_{\mathrm{T}}, \mathrm{V}_{\mathrm{N}} \in \mathrm{V}\right)$. 
Am. J. Applied Sci., 8 (4): 382-392, 2011

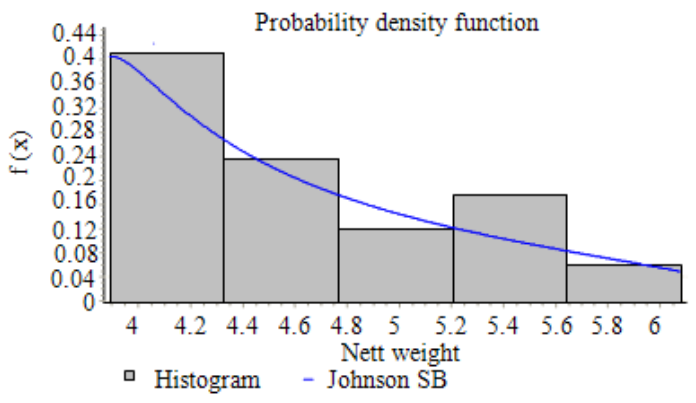

Fig. 3: Johnson SB distribution for nett weight of customers' demands (in kilograms) in normal weather operations

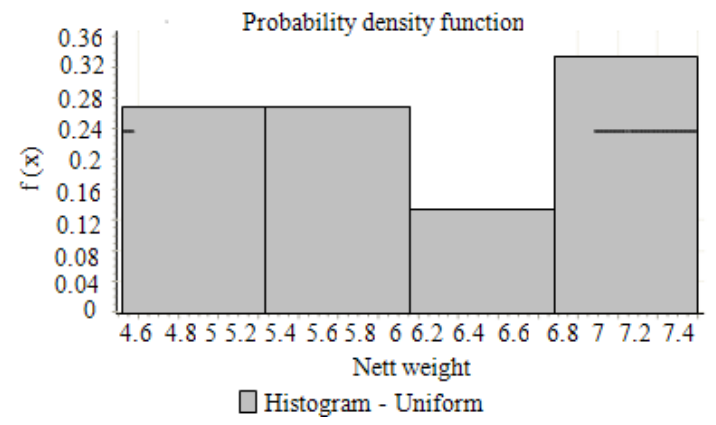

Fig. 4: Uniform distribution for nett weight of customers' demands in rainy operation days

Table 3: Goodness of fit for Johnson SB distribution of customers' demands in normal weather operations

\begin{tabular}{llll}
\hline Methods & KS & AD & CS \\
\hline Statistic & 0.10018 & 0.23275 & 0.21946 \\
Critical value & 0.31796 & 2.5018 & 5.9915 \\
Degree of freedom & - & - & 2 \\
$p$-value & 0.98885 & - & 0.89608 \\
Reject? & No & No & No \\
Rank & 2 & 1 & 3 \\
\hline
\end{tabular}

Given a connected graph $\mathrm{G}=(\mathrm{V}, \mathrm{E} \cup \mathrm{A})$, with $\mathrm{V}$ as the set of nodes (vertices), $\mathrm{E}$ is the set of edges $(\mathrm{E} \subseteq \mathrm{VxV})$ and $\mathrm{A}$ is a set of $\operatorname{arcs}(\mathrm{A} \subseteq \mathrm{VxV})$. CARP has a traversal cost for each edge and arc with demand, $q_{i j} \geq$ 0 for each edge $(i, j)$ which must be served by one vehicle once without exceeds the capacity, W. The problem is to find a number of circuits each of which passes through the depot which satisfies demands at minimal total cost. We denote $c_{i j}$ as the cost of an edge $(\operatorname{arc})(i, j) \in E(A)$ and $x_{i j k}$ as the number of times edge $(\operatorname{arc})(i, j) \in E \cup A$ is traversed in trip k. Furthermore, for mesh network architecture, the vehicle must start its collection from any corner vertex and moves along the backbone before it choose the outer joint. When the vehicle is inside the network, the vehicle may choose either one of three arcs to begin collection at the inner area. Objective function of CARP as formulated is given by:

Minimize $\sum_{(\mathrm{i}, \mathrm{j}) \in \mathrm{E}} \sum_{\mathrm{k}=1}^{\mathrm{K}} \mathrm{c}_{\mathrm{ij}} \mathrm{x}_{\mathrm{ijk}}$

Subject to:

$\sum_{\mathrm{p} \in \mathrm{V}} \mathrm{x}_{\mathrm{ipk}}=\sum_{\mathrm{p} \in \mathrm{V}} \mathrm{x}_{\mathrm{pik}} \forall \mathrm{i} \in \mathrm{V}, \mathrm{k}=1,2, \ldots . ., \mathrm{k}$

$\sum_{\mathrm{k}=1}^{\mathrm{K}} \mathrm{y}_{\mathrm{jik}}=1, \forall(\mathrm{i}, \mathrm{j}) \in \mathrm{R}$

$\mathrm{x}_{\mathrm{ijk}} \geq \mathrm{y}_{\mathrm{ijk}}, \forall(\mathrm{i}, \mathrm{j}) \in \mathrm{R}, \mathrm{k}=1,2, . ., \mathrm{k}$,

$\sum_{(\mathrm{i}, \mathrm{j}) \in \mathrm{R}} \mathrm{q}_{\mathrm{ij}} \mathrm{y}_{\mathrm{ijk}} \leq \mathrm{W}, \mathrm{k}=1,2, . ., \mathrm{k}$

$r\left[\sum_{(i, j) \in R} q_{i j} y_{i j k}\right]+\sum_{(i, j) \in R} q_{i j} y_{i j k} \leq W$,

$\mathrm{r}[\min , \max ]=\mathrm{t}[0.1,1.0], \mathrm{k}=1,2, \ldots, \mathrm{K}$

Equation 1 ensures route discrete continuity. Equation 2 states that each edge with positive demand is serviced exactly once. Inequation (3) guarantees that the traversal circuit $k$ covers the edge $(i, j) \in R$ if it delivers its demand. Vehicle capacity is not violated on account of inequation (4) and (5) where $r$ is rainy weightage that increase the waste weight depends on rain drops and the scale is $0.1 \leq \mathrm{r} \leq 1.0$. Inequation (4) formulates the CARPSD in normal days that followed Johnson SB distribution with $\gamma=0.83016, \delta=0.71672$, $\lambda=2.8661$ and $\xi=3.7468$ as depicts below in Fig. 3. The Probability Density Function (PDF) of Johnson SB is given by:

$$
f(x)=\frac{\delta}{\lambda \sqrt{2 \pi} z(1-z)} \exp \left(-\frac{1}{2}\left(\gamma+\delta \ln \left(\frac{z}{1-z}\right)\right)^{2}\right)
$$

where, $\xi \leq x \leq \xi+\lambda$. Three goodness of fit (Kolmogorov-Smirnov, KS; Anderson-Darling, AD; and Chi-squared, CS) are tested to conform the proposed distribution. The result is shown in Table 3.

In contrary, inequation (5) formulates the CARPSD in rainy days that tend to fall in Uniform distribution with $\mathrm{a}=4.4512$ and $\mathrm{b}=7.4988$ as displays in Fig. 4 . The PDF of Uniform distribution is given by $f(x)=\frac{1}{b-a}$; where $a \leq x \leq b$. Then three goodness of fit (KS, AD and CS) are tested to accept the suggested distribution. We display the result in Table 4. 
Am. J. Applied Sci., 8 (4): 382-392, 2011

Table 4: GOF tests for Uniform distribution on net weight of customers' demands in rainy operation days

\begin{tabular}{llll}
\hline Methods & KS & AD & CS \\
\hline Statistic & 0.12385 & 0.24128 & 0.08782 \\
Critical value & 0.3376 & 2.5018 & 3.8415 \\
$p$-value & 0.95355 & - & 0.76697 \\
Degree of freedom & - & - & 1 \\
Reject? & No & No & No \\
Rank & 3 & 2 & 10 \\
\hline
\end{tabular}

The next constraints of CARP are:

$\mathrm{M} \sum_{(\mathrm{i}, \mathrm{j}) \in \mathrm{V}[\mathrm{S}]} \mathbf{x}_{\mathrm{jik}} \geq \sum_{(\mathrm{j}, \mathrm{p}) \in \mathrm{S}} \mathbf{x}_{\mathrm{j} \mathrm{pk}}$

$\mathrm{y}_{\mathrm{ijk}} \in\{0,1\}, \forall(\mathrm{i}, \mathrm{j}) \in \mathrm{R}, \mathrm{k}=1,2, \ldots, \mathrm{K}$

$\mathrm{x}_{\mathrm{ijk}} \in \mathrm{Z}^{+}, \forall(\mathrm{i}, \mathrm{j}) \in \mathrm{R}, \mathrm{k}=1,2, \ldots, \mathrm{K}$

Inequation (6) prohibits the formation of (infeasible) subtours. Integrality restrictions are given in Eq. 7 and 8:

$Y_{i j k}=\left\{\begin{array}{c}I \text { if the edge }(\operatorname{Arc})(i, j) \in R \\ \text { is covered in trip } k \\ 0 \text { otherwise }\end{array}\right.$

$\mathrm{M}$ is a large constant greater than or equal to the sum of traversals of edges and arcs in a given $\mathrm{S} \subseteq \mathrm{R}, \mathrm{V}[\mathrm{S}]$ is the set of nodes incident to the arc set $\mathrm{S}, \mathrm{k}$ denotes a trip and $\mathrm{K}$ is the maximum number of trips allowed.

Incorporating time element into CARPTW is obviously difficult as it needs many time subsets to consider. In waste collection, total operation time including service time, routing time and delivery time. Service time is the time taken by the vehicle to collect, load and compress the garbage bags. In real-life operation and especially within a dynamic setting the on-site service times are subject to stochasticity.

In most distribution contexts, the on-site service time in municipal waste collection involves picking-up and compressing the household refusals. In most cases, these activities require human interaction of some form. The time spent on this situation could of course vary from few seconds to several minutes. Larsen (2001) convinced that using a constant service times might not be the most appropriate approach. Routing time is the time taken by the vehicle to move from one arc to another arc. Meanwhile delivery time is the time taken by the vehicle from the last customer to the dumpsite for disposal activity. By this means, we define the total operation time as:

$$
\begin{gathered}
\mathrm{OT}_{\mathrm{x}_{\mathrm{j} k}}=\sum_{(\mathrm{i}, \mathrm{j}) \in \mathrm{E}, \mathrm{k}=1}^{\mathrm{K}} \mathrm{ST}_{\mathrm{x}_{\mathrm{j} \mathrm{k}}}+\mathrm{DT}_{\mathrm{k}} \\
\sum_{(\mathrm{i}, \mathrm{j}) \mathrm{E}, \mathrm{k}=1}^{\mathrm{K}} \mathrm{ST}_{\mathrm{x}_{\mathrm{jik}}}<\mathrm{OT}_{\mathrm{x}_{\mathrm{jik}}} \leq 9
\end{gathered}
$$

$\sum_{(i, j) \in E, k=1}^{K} S_{x_{i j k}}$ is stochastic service time that followed Log-Logistic 3P with parameters $\mathrm{a}=4.6384, \mathrm{~b}=$ 8.0149 and $r=93.422$ in normal days. Meanwhile in rainy days operation, this variable is stochasticity to Log-Logistic 3P with parameters $\mathrm{a}=6.0999, \mathrm{~b}=$ 14.888 and $r=95.496$. Inequation (10) ensures the service times is not exceed the allowed operation time, $\mathrm{OT}_{\mathrm{xijk}}$. In our case, $\mathrm{OT}_{\mathrm{xijk}}$ is considered as hard time window when only 9 hours allowed as working time per day. Furthermore, the disposal activity must be completely done before last hour (at $5 \mathrm{pm}$ ) as the dumpsite will be shut off due to security reason. We assumed delivery time, DT as random because the vehicle chooses the same path every delivery time and this parameter is varied by considering traffic congestion. We applied constraints (1)-(8) in modeling CARPTW. However, in programming context, we developed both models (CARPTW and CARPSD) separately for comparison purpose but both models are designed to produce feasible routing solution at minimum cost by using the same objective function.

Relaxation time windows: In previous discussions, we highlighted that our vehicle operations are comply with certain time windows. The critical measurement in this operation is whether our vehicle can meet delivery time, DT without surpass the lateness or not. One difficulty during disposal activity is inconsistent rules enforcement at management level of the disposal site. The time window constraints as discussed in previous sections are hard constraints, which cannot be violated. This hard time window constraints increase the complexity of determining optimal delivery routing. However, in real situation the vehicles are permitted to dispose if they are not too late. In order to tackle this problem, we apply relaxation to soften hard time window. Soft time window in contrast, constraints can be violated but with a penalty cost. When the vehicle arrives within acceptable late delivery, it is still allowed to dispose off but with a penalty cost. A benchmark study is done by Nazif and Lee (2010) on VRP with Time Windows (VRPTW) and solves it with genetic algorithm approach. Another studies that have considered vehicle routing problem with time window constraints and have constructed penalty costs to reflect 
violation of these time windows can be seen in Koskosidis et al., 1992; and Sexton and Choi, 1986. We depict the relationship between penalty cost and arrival time in Fig. 5.

Penalty cost for late delivery: In the Fig. 5 above, arrival within normal time window is depicts as $[0, \mathrm{~s}]$. However, time window is violated within acceptable delay is shown in $(\mathrm{s}, \mathrm{S}]$. Vehicle operators will be charge a penalty cost of $P_{1}$ if the arrival time is within this soft time window. Relation between violations of hard time window and penalty cost is shown by $\mathrm{P}_{2}$ if arrival is too late with unacceptable delay, $A_{t}>S$. The penalty cost, due to violating the upper bound of the time window can be formulated as:

$$
P=\left\{\begin{array}{c}
0 \text { if } A_{t}=[0, s] \\
P_{1} \text { if } A_{t}=A(s, S] \\
P_{2} \text { if } A_{t}>S
\end{array}\right.
$$

In order to determine delivery time, let DT denote the delivery time on the link $\left(\mathrm{v}_{\mathrm{n}}, \mathrm{v}_{\mathrm{o}}\right)$. Let $\mathrm{A}$ and $\mathrm{A}$ ' denote the set of links without traffic congestion and with probability of traffic congestion respectively, $A \subseteq A^{\prime}$. For every link $\left(v_{n}, v_{0}\right) \in A$, delivery time on link $\left(\mathrm{v}_{\mathrm{n}}, \mathrm{v}_{\mathrm{o}}\right)$ can be expressed as $\mathrm{DT}_{\mathrm{no}}=\beta_{\mathrm{o}}$, where $\beta_{\mathrm{o}}$ is a time parameter. Assume some links of $A^{\prime}$ have the probability $\mathrm{p}$ of being congested. For every link $\left(\mathrm{v}_{\mathrm{n}}\right.$, $\left.\mathrm{v}_{\mathrm{o}}\right) \in \mathrm{A}^{\prime}$, delivery time, $\mathrm{DT}_{\mathrm{no}}=\mathrm{p} \beta_{\mathrm{o}}+\beta_{\mathrm{o}}$ :

$$
\mathrm{DT}_{\mathrm{no}}=\left\{\begin{array}{c}
\beta_{0} \text { if }\left(\mathrm{V}_{\mathrm{n}}, \mathrm{V}_{\mathrm{o}}\right) \in A \\
\mathrm{p} \beta_{0}+\beta_{0} \text { if }\left(\mathrm{V}_{\mathrm{n}}, \mathrm{V}_{0}\right) \in \mathrm{A}
\end{array}\right.
$$

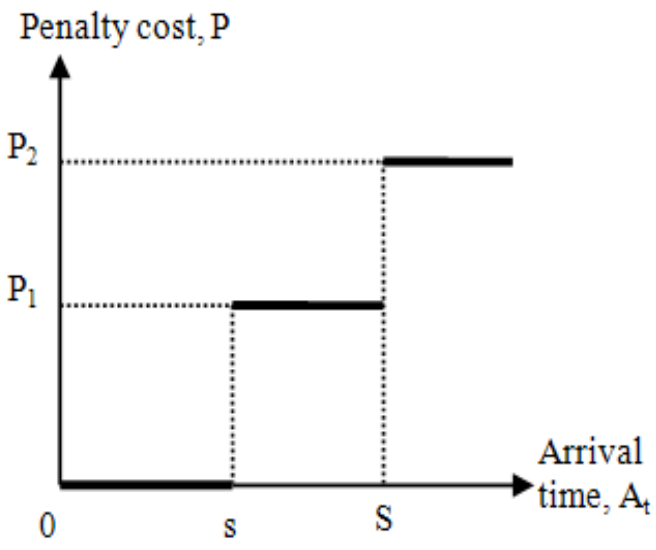

Fig. 5: The relationship between arrival time and penalty cost
We extended this formula to calculate delivery cost, DC from node $\mathrm{v}_{\mathrm{n}}$ (last collected customer on link) to node $v_{o}$ (dumpsite). For every link $\left(v_{n}, v_{o}\right) \in A$, delivery cost on link $\left(\mathrm{v}_{\mathrm{n}}, \mathrm{v}_{\mathrm{o}}\right)$ can be expressed as $\mathrm{DC}_{\mathrm{no}}=\beta_{\mathrm{o}}$, where $\beta_{\mathrm{o}}$ is a time parameter. Delivery cost, $\mathrm{DC}_{\mathrm{no}}$ which affected by traffic congestion is given by $\mathrm{DC}_{\mathrm{no}}=\mathrm{p} \beta_{\mathrm{o}}+\beta_{\mathrm{o}}$ :

$\mathrm{DC}_{\mathrm{no}}=\left\{\begin{array}{c}\beta_{\mathrm{o}} \mathrm{c}_{\mathrm{no}} \text { if }\left(\mathrm{v}_{\mathrm{n}}, \mathrm{v}_{\mathrm{o}}\right) \in A \\ \left(\mathrm{p} \beta_{\mathrm{o}}+\beta_{\mathrm{o}}\right) \mathrm{c}_{\mathrm{no}} \text { if }\left(\mathrm{v}_{\mathrm{n}}, \mathrm{v}_{\mathrm{o}}\right) \in \mathrm{A}^{\prime}\end{array}\right.$

Because of the randomness of delivery time on links, arrival time at dumpsite is also characterized as random variable. Since the real-time traffic conditions for every link $\left(\mathrm{v}_{\mathrm{n}}, \mathrm{v}_{\mathrm{o}}\right)$ is unknown before departure from node $\mathrm{v}_{\mathrm{n}}$, arrival time at the $\mathrm{v}_{\mathrm{o}}$ (dumpsite) is difficult to predict. We defined $\mathrm{DT}_{\text {no }}=(\mathrm{s}, \mathrm{S}]$ as acceptable lateness which to be the amount of lateness between the normal time windows upper bound, $\mathrm{s}<\mathrm{DT}_{\mathrm{no}}=\mathrm{S}$ and the actual arrival time. We impose this lateness delivery as a soft time window constraint that can be violated. However, too late delivery is considered as hard time window. In real life scenario, the vehicle is totally prohibited to enter the landfill if its surpass $7 \mathrm{pm}$. Thus, the vehicle must travel back to the depot with incomplete task of that day. Consequently, penalty cost for incomplete mission would be higher (depict as $\mathrm{P}_{2}$ in Fig. 5). The penalty cost which incurred into delivery cost is given by:

$$
\mathrm{DC}_{\mathrm{no}}=\left\{\begin{array}{c}
\beta_{\mathrm{o}} \mathrm{C}_{\mathrm{no}} \text { if } 0 \leq \mathrm{DT}_{\mathrm{no}} \leq \mathrm{s} \\
\text { for }\left(\mathrm{v}_{\mathrm{n}}, \mathrm{v}_{0}\right) \in \mathrm{A} \\
\beta_{\mathrm{o}} \mathrm{c}_{\mathrm{no}}+\mathrm{P}_{\mathrm{I}} \text { if } \mathrm{s}<\mathrm{DT}_{\mathrm{no}} \\
\leq \mathrm{s} \text { for }\left(\mathrm{v}_{\mathrm{n}}, \mathrm{v}_{0}\right) \in \mathrm{A} \\
\beta_{\mathrm{o}} \mathrm{c}_{\mathrm{no}}+\mathrm{P}_{2} \text { if } \mathrm{DT} \mathrm{T}_{\mathrm{no}} \\
>\mathrm{S} \text { for }\left(\mathrm{v}_{\mathrm{n}}, \mathrm{v}_{0}\right) \in \mathrm{A} \\
\left(\mathrm{p} \beta_{\mathrm{o}}+\beta_{\mathrm{o}}\right) \mathrm{c}_{\mathrm{no}} \text { if } 0 \leq \mathrm{DT}_{\mathrm{no}} \\
\leq \mathrm{s} \text { for }\left(\mathrm{v}_{\mathrm{n}}, \mathrm{v}_{0}\right) \in \mathrm{A} \\
\left(\mathrm{p} \beta_{\mathrm{o}}+\beta_{\mathrm{o}}\right) \mathrm{c}_{\mathrm{no}}+\mathrm{P}_{1} \text { if } \mathrm{s}<\mathrm{DT}_{\mathrm{no}} \\
\leq \mathrm{S} \text { for }\left(\mathrm{v}_{\mathrm{n}}, \mathrm{v}_{0}\right) \in \mathrm{A} \\
\left(\mathrm{p} \beta_{\mathrm{o}}+\beta_{\mathrm{o}}\right) \mathrm{c}_{\mathrm{no}}+\mathrm{P}_{2} \text { if } \mathrm{s}<\mathrm{DT}_{\mathrm{no}} \\
>\mathrm{s} \text { for }\left(\mathrm{v}_{\mathrm{n}}, \mathrm{v}_{0}\right) \in \mathrm{A}
\end{array}\right.
$$

Heuristic solution: It is necessary to generate a number of solutions to initialize the main search process. The choice of the initial solution is known to be important. Perttunen (1994) investigated whether the use of a constructive heuristic leads to better results than using random initial solutions. He found that the use of initial solutions generated by applying a constructive 
heuristic, instead of a random initial solution, typically improve the performance of the algorithm. In this study, we generated the initial solution by using nearest procedure based on highest demand/cost ratio (NPHDC). NPHDC is a simple heuristic approach and it is similar to Nearest Neighbor (NN) and Cheapest Edge (CE) method. The different between the both methods is only on the move criterion, but the algorithm is almost similar. The NPHDC used highest demand (or demand ratio) to move from one node to another, while $\mathrm{CE}$ used least cost as its priority.

By using NPHDC, the vehicle starts travelling from the depot. It will moves from one arc to another with the required arc being served in a route that has the highest demand/cost. It will continue until all arcs have been served. When no remaining required arcs can be feasibly added to the route, the route is completed by the vehicle returns to the depot through minimum cost of deadheading path. We implemented nearest procedure in order to find the first service route after traveling from the depot. Notations of variables are as follows:

$\mathrm{y}_{\text {init }}=0$, number of routes before first cycle starts

$\mathrm{q}_{\text {init }}=0$, initial capacity for one vehicle before first cycle starts

$\mathrm{c}_{\text {init }}=0$, initial cost for one vehicle

before first cycle starts

$\mathrm{c}_{\mathrm{ij}}$, cost from point $\mathrm{i}$ to point $\mathrm{j}$

$\mathrm{E}_{\mathrm{i}+1}$, next successor edge

$y=y_{\text {init }}+1$, count of routes after each cycle starts

$\mathrm{q}_{\text {new }}=\mathrm{q}_{\text {init }}+\mathrm{q}_{\mathrm{ij}}$, capacity at route $\mathrm{ij}$

$\mathrm{q}_{\text {balnew }}=\mathrm{q}-\mathrm{q}_{\text {new }}$, balance of capacity

after collection at route ij

$c_{\text {new }}=c_{\text {init }}+c_{i j}$, sum of route cost from depot to point $\mathrm{i}$ to point $\mathrm{j}$

$\mathrm{c}=\mathrm{c}_{\text {init }}+\mathrm{c}_{\text {new }}$, increase of cost while increase the number of routes

$\mathrm{q}_{\text {new }} \mathrm{q}_{\text {new }}:=\sum_{\mathrm{q}=\mathrm{i}}^{\mathrm{n}} \mathrm{i}+1$, sum of capacity from

point $\mathrm{i}$ to point $\mathrm{n}$, assigned to

capacity variable $\mathrm{q}_{\mathrm{balnew}}:=\mathrm{w}-\sum_{\mathrm{q}=\mathrm{i}}^{\mathrm{n}} \mathrm{i}+1$, balance capacity

from point $\mathrm{i}$ to point $\mathrm{n}$, assigned

to balance capacity variable

$\mathrm{C}_{\text {new }}:=\sum \mathrm{c}_{\mathrm{ij}}$, sum of all route cost,

assigned to cost variable

$\mathrm{q}_{\text {init }}:=\mathrm{q}_{\text {new }}$, new capacity reassign to

initial capacity after each cycle

$\mathrm{c}_{\text {init }}:=\mathrm{c}_{\text {new }}$, new cost reassign to

initial cost after each cycle

$\mathrm{q}_{\text {balnew }} \geq \mathrm{q}$, decision operator

for capacity

NPHDC build a feasible route by inserting at every iteration an unrouted customer into a previous continuity serviced routes. This process is performed one route a time:

Step 1: Input $\mathrm{W}$. Generate random number, $\mathrm{V}$ and $\mathrm{E}$; $\operatorname{depot} \mathrm{O}=$ initial, $\mathrm{y}_{\text {init }}=0, \mathrm{q}_{\text {init }}=0, \cos \mathrm{c} \mathrm{c}_{\text {init }}=0$, capacity $\mathrm{q}=\mathrm{W}$, trip $\mathrm{k}=0$.

Step 2: From $\mathrm{O}, \mathrm{k}:=\mathrm{k}+1$, find the successor customer, $\mathrm{V}_{\mathrm{i}}$ using NPHDC, compare and choose the best $\mathrm{V}_{\mathrm{i}}$ and $\mathrm{E}_{(\mathrm{i}, \mathrm{j})}$. Set $\mathrm{y}=\mathrm{y}_{\text {init }}+1$, count new weight, $\mathrm{q}_{\text {new }}=\mathrm{q}_{\text {init }}+\mathrm{q}_{\mathrm{ij}}$ and $\mathrm{q}_{\text {balnew }}=$ $\mathrm{W}-\mathrm{q}_{\text {new. }}$. Count new cost, $\mathrm{c}_{\text {new }}=\mathrm{c}_{\text {init }}+\mathrm{c}_{\mathrm{ij}}$.

Step 3: If $\mathrm{q}_{\text {balnew }}<\mathrm{W}$, then check the next successor,

$\mathrm{V}_{\mathrm{i}+1} . \quad$ Assigned $\mathrm{q}_{\text {new }}:=\sum_{\mathrm{q}=\mathrm{i}}^{\mathrm{n}} \mathrm{i}+1$ and $\mathrm{q}_{\mathrm{balnew}}:=\mathrm{W}-\sum_{\mathrm{q}=\mathrm{i}}^{\mathrm{n}} \mathrm{i}+1$. If $\mathrm{q}_{\text {balnew }} \leq 0$ then stop and check all serviced $\mathrm{E}_{(\mathrm{i}, \mathrm{j})}$. If $\mathrm{E}_{(\mathrm{i}, \mathrm{j})}=\mathrm{E}_{(\mathrm{n}-1, \mathrm{n})}$ then go to Step 4. If $\mathrm{E}_{(\mathrm{i}, \mathrm{j})} \neq \mathrm{E}_{(\mathrm{n}-1, \mathrm{n})}$ then go to Step 2. Assigned $\mathrm{y}_{\text {init }}:=\mathrm{y}$. Terminate all served edges and go to Step 2.

Step 4: Repeat Step 3 until all served $E_{n}$. Assigned $c_{\text {new }}$ $:=\mathrm{C}_{\text {new }}:=\sum \mathrm{c}_{\mathrm{ij}}, \mathrm{q}_{\text {init }}:=\mathrm{q}_{\text {new }}$ and $\mathrm{c}_{\text {init }}:=\mathrm{c}_{\text {new }}$. Void all served y. Count all variables.

\section{RESULTS}

The performance of NPHDC has been tested and evaluated. We modeled our case of operational waste collection for one identical truck is likely similar to road layout in our case study. This Mesh Network (MN) of CARP graph for 33 nodes and 54 arcs is shown in the Fig. 6. 


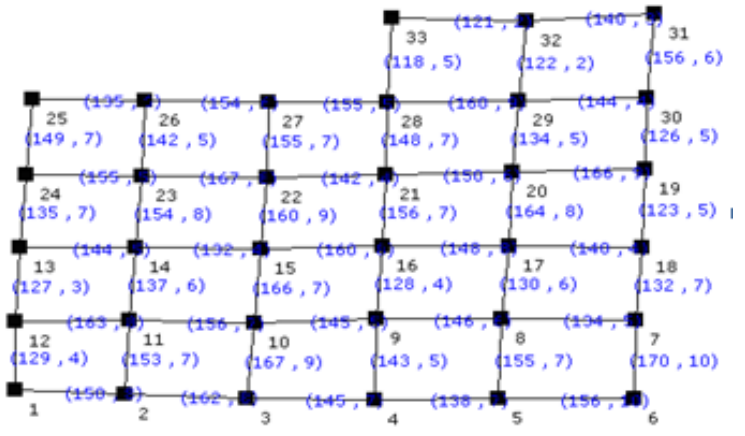

Fig. 6: Mesh network for 33 nodes and 54 arcs

\begin{tabular}{|c|c|c|c|c|}
\hline $\mathrm{Vx}$ & $X(i, j)$ & $\mathrm{q}_{\mathrm{ij}}$ & $\mathrm{c}_{\mathrm{ij}}$ & $\mathrm{q}_{\mathrm{ij}} / \mathrm{c}_{\mathrm{ij}}$ \\
\hline \multirow[t]{2}{*}{$\overline{1}$} & $X(1,2)$ & 150 & 8 & 18.75 \\
\hline & $X(1,12)$ & 129 & 4 & 32.25 \\
\hline \multirow[t]{2}{*}{6} & $X(6,5)$ & 156 & 10 & 15.60 \\
\hline & $X(6,7)$ & 170 & 10 & 17.00 \\
\hline \multirow[t]{2}{*}{25} & $X(25,24)$ & 149 & 7 & 21.30 \\
\hline & $X(25,26)$ & 135 & 6 & 22.50 \\
\hline \multirow[t]{2}{*}{31} & $\mathrm{X}(31,30)$ & 156 & 6 & 26.00 \\
\hline & $X(31,32)$ & 140 & 3 & 46.70 \\
\hline \multirow[t]{2}{*}{33} & $X(33,28)$ & 118 & 5 & 23.60 \\
\hline & $\mathrm{X}(33,32)$ & 121 & 2 & 60.50 \\
\hline
\end{tabular}

Table 6: Switching procedure according tohighest demand

\begin{tabular}{lllll}
\hline $\mathrm{n}$ & $\mathrm{X}(\mathrm{i}, \mathrm{j})$ & $\mathrm{qij}$ & $\mathrm{cij}$ & $\mathrm{qij} / \mathrm{cij}$ \\
\hline 15 & $\mathrm{X}(15,10)$ & 166 & 7 & 23.7 \\
& $\mathrm{X}(15,14)$ & 132 & 4 & 33.0 \\
& $\mathrm{X}(15,16)$ & 160 & 8 & 20.0 \\
& $\mathrm{X}(15,22)$ & 160 & 9 & 17.8 \\
\hline
\end{tabular}

Table 7: Initial solution of different problem instances for normal and rainy weather

\begin{tabular}{|c|c|c|c|c|c|}
\hline \multicolumn{2}{|c|}{$\mathrm{MN}$} & \multirow{2}{*}{$\begin{array}{l}\text { Capacity, } \\
\text { W (kg) }\end{array}$} & \multicolumn{3}{|c|}{ Normal } \\
\hline$\# \mathrm{n}$ & $\# \mathrm{R}$ & & $\mathrm{c}$ & $\# \mathrm{~K}$ & CPU time (ms) \\
\hline 10 & 13 & 1000 & 141 & 2 & 17 \\
\hline 15 & 22 & 3000 & 264 & 2 & 4 \\
\hline 33 & 54 & 5100 & 480 & 3 & 21 \\
\hline 50 & 85 & 9000 & 878 & 2 & 1028 \\
\hline 10 & 13 & 1000 & 286 & 4 & 6 \\
\hline 15 & 22 & 3000 & 286 & 3 & 7 \\
\hline 33 & 54 & 5100 & 480 & 2 & 7 \\
\hline 50 & 85 & 9000 & 965 & 3 & 3033 \\
\hline
\end{tabular}

We determined the characteristics of moves to some rules:

- The trip must starts at any corner vertex. In the above example the first move must begin at either node $1,6,25,31$ or 33 . We demonstrate the procedure in Table 5. Arc X $(33,32)$ is chosen according to NPHDC

- From vertex corner, the chosen of moving neighborhood is based on the NPHDC
- If collection of the truck is reaching its capacity, the criteria suddenly swift to highest demand. This variable is called pre-capacity, $r$ which is $r<\mathrm{W}$. Let say the truck at node 15 and the pre-capacity, $r$ is set to $450 \mathrm{~kg}$ with initial carried quantity $\mathrm{q}=430$ $\mathrm{kg}$ and maximum capacity, $\mathrm{W}=600 \mathrm{~kg}$. At node 15 , the options are as shown in Table 6. Arc X (15, 10 ) is chosen with aim to maximize the collected demand without exceeding truck's capacity $\mathrm{W}$, that is $\mathrm{q}=596 \mathrm{~kg}$ which is less than $\mathrm{W}=600 \mathrm{~kg}$. Instead of choosing arc $\mathrm{X}(15,14)$ due to its highest ratio, however the capacity is not fully utilize since we got the total carried quantity q $=562 \mathrm{~kg}$ only.

We developed a computer program using $\mathrm{C \#}$ language and run on Intel Celeron processor with 504 MB RAM. We set the customers' demands followed Johnson SB distribution with $\gamma=0.83016, \delta=0.71672$, $\lambda=2.8661$ and $\xi=3.7468$ in normal operation days. Meanwhile in rainy days, the customers' demands followed Uniform distribution with $\mathrm{a}=4.4512$ and $\mathrm{b}=$ 7.4988. We also tested the algorithm with different sets of capacity, c, number of nodes and arcs. The smallest problem instances were set to 10 nodes and the biggest problem instances were set to 50 nodes. Our real case which is 33 nodes is considered as a moderate problem of CARP. The result is displays in Table 7.

\section{DISCUSSION}

In this study, we solved different set of mesh networks of CARP models namely as CARPSD and CARPTW, where both models were designed based on different weather-type (normal and rainy). The developed models represent the real case of truck operation in waste collection specifically in Johor Bahru, Malaysia. We redefined the CARP almost similar to a mesh network and incorporating stochastic element in customers' demands and time windows. Objectively, CARPSD and CARPTW were redefined to present a real-life problem of waste collection and to provide adequate information in modeling phase. The objective in this study is to find the feasible solution using nearest procedure based on highest demand/cost (NPHDC) heuristic. This heuristic works in conjunction with switching rules in order to maximize the collection without exceeding vehicle's capacity. In general, by omitting the third trial, the sample results of 10,15 and 50 nodes showed that the same mesh network of CARP/CARPTW produced higher total cost and more trips are needed to complete all collection when operating in rainy days compared to normal days. We assumed that 10 and 15 nodes instances as low level 
problem, 33 as intermediate and 50 as high problem of mesh network to solve.

\section{CONCLUSION}

Our algorithm seems to produce the static result after considerably enough ten runs. The preliminary results are considered reliable and feasible as we expected that the higher total cost and more trips in rainy day operation. As far to this level, the algorithm produced consistent and stable output. The tested of a real scenario for truck operation which consists of 33 nodes and 54 arcs is considered as moderate CARP test instances. Moreover, the algorithm is good from stability point of view. We also showed that all algorithms could be used to yield reasonably good results for the standard CARP model. The test on a larger customer, perhaps up to 100 nodes should be extended further to find more variation in the results. In addition, feasible solution based on Nearest Procedure of the Highest Demand/Cost (NPHDC) also good in appointing a starting point in the entire searching process. Lastly, we developed the algorithm without any intention to compete with other heuristic or metaheuristic methods.

\section{ACKNOWLEDGEMENT}

We gratefully acknowledge the Ministry of Higher Education of Malaysia (MOHE), Ministry of Science, Technology and Innovation of Malaysia (MOSTI) and Research Management Centre UTM for their grant funding and administration supported. The second author also would like to thank Universiti Malaysia Perlis (UNIMAP) for financial aid and Syarikat Perniagaan Zawiyah Sdn. Bhd. for their cooperation in this research. This research is a part of IRPA RMK-8 project (09-02-06-144EAR) funded by MOSTI.

\section{REFERENCES}

Amponsah, S.K. and S. Salhi, 2004. The investigation of a class of capacitated arc routing problems: The collection of garbage in developing countries. Waste Manage., 24: 711-721. DOI: 10.1016/j.wasman.2004.01.008

Bautista, J., E. Fernández and J. Pereira, 2008. Solving an urban waste collection problem using ants heuristics. Comput. Oper. Res., 35: 3020-3033. DOI: 10.1016/j.cor.2007.01.029
Beltrami, E.J. and L.D. Bodin, 1974. Networks and vehicle routing for municipal waste collection. Networks, 4: 65-94. DOI: 10.1002/net.3230040106

Christiansen, C.H., J. Lysgaard and S. Wohlk, 2009. A branch-and-price algorithm for the capacitated arc routing problem with stochastic demands. Operat. Res. Lett., 37: 392-398. DOI: 10.1016/j.orl.2009.05.008

Chu, F., N. Labadi and C. Prins, 2006. A scatter search for the periodic capacitated arc routing problem. European J. Operat. Res., 169: 586-605.

Golden, B.L. and R.T. Wong, 1981. Capacitated arc routing problems. Networks, 11: 305-315. DOI: $10.1002 /$ net.3230110308

Gouveia, L., M.C. Mourao and L.S. Pinto, 2010. Lower bounds for the mixed capacitated arc routing problem. Comput. Operat. Res., 37: 692-699. DOI: 10.1016/j.cor.2009.06.018

Hertz, A., G. Laporte and M. Mittaz, 2000. A tabu search heuristic for the capacitated arc routing problem. Operat. Res., 48: 129-135.

Hsu, C.I., S.F. Hung and H.C. Li, 2007. Vehicle routing problem with time-windows for perishable food delivery. J. Food Eng., 80: 465-475. DOI: 10.1016/j.jfoodeng.2006.05.029

Irhamah, I. and Z. Ismail, 2009. A breeder genetic algorithm for vehicle routing problem with stochastic demands. J. Applied Sci. Res., 5: 1998-2005.

Ismail, Z. and Irhamah, 2008. Solving the vehicle routing problem with stochastic demands via hybrid genetic algorithm-tabu search. J. Math. Stat., $\quad 4$ : 161-167. DOI: 10.3844/jmssp.2008.161.167

Koskosidis, Y.A., W.B. Powell and M.M. Solomon, 1992. An optimization-based heuristic for vehicle routing and scheduling with soft time window constraints. Trans. Sci., 26: 69-85. DOI: $10.1287 /$ trsc. 26.2 .69

Lacomme, P., C. Prins and R.C. Wahiba, 2005. Evolutionary algorithms for periodic arc routing problems. European J. Operat. Res., 165: 535-553.

Larsen, A., 2001. The Dynamic Vehicle Routing Problem. Bookbinder Hans Meyer. http://portals.dmst.aueb.gr/scm/theses/PhD_DVRP Larsen.pdf

Letchford, A.N. and A. Oukil, 2009. Exploiting sparsity in pricing routines for the capacitated arc routing problem. Comput. Operat. Res., 36: 2320-2327. DOI: 10.1016/j.cor.2008.09.008

Nazif, H. and L.S. Lee, 2010. Optimized crossover genetic algorithm for vehicle routing problem with time windows. Am. J. Applied Sci., 7: 95-101. DOI: 10.3844/ajassp.2010.95.101 
Am. J. Applied Sci., 8 (4): 382-392, 2011

Perttunen, J., 1994. On the significance of the initial solution in travelling salesman heuristics. J. Operat. Res. Soc., 45: 1131-1140.

Sexton, T.R. and Y.M. Choi, 1986. Pickup and delivery of partial loads with soft time windows. Am. J. Math. Manage. Sci., 6: 369-398.
Santos, L., J. Coutinho-Rodrigues and J.R. Current, 2010. An improved ant colony optimization based algorithm for the capacitated arc routing problem. Trans. Res. Part B: Methodolog., 44: 246-266. DOI: $10.1016 /$ j.trb.2009.07.004 